\title{
Polycyclic Aromatic Hydrocarbons and Breast Cancer: A Review of the Literature
}

\author{
Jessica Korsh Allison Shen Kristen Aliano Thomas Davenport \\ Long Island Plastic Surgical Group, Garden City, NY, USA
}

\section{Keywords}

Polycyclic aromatic hydrocarbon - PAH - Breast cancer

\section{Summary}

Polycyclic aromatic hydrocarbons (PAHs) exist and persist in the atmosphere due to the incomplete combustion of fossil fuels, and are established human carcinogens. The influence of PAHs on the development of breast cancer, the most commonly diagnosed cancer in women worldwide, remains unclear. As established risk factors only account for approximately $41 \%$ of the breast cancer cases in the USA, researchers have sought to uncover environmental factors involved in breast cancer development. The breasts are particularly susceptible to aromatic carcinogenesis, and the implementation of biomarkers has provided promising insights regarding $\mathrm{PAH}$ DNA adducts in breast cancer. The use of biomarkers measuring PAH-DNA adducts assesses exposure to eliminate the bias inherent in self-reporting measures in case-control studies investigating the link between PAHs and cancer. Adduct levels reflect exposure dose as well as how the body responds to this exposure, which is partially attributable to genetic variability. Evidence suggests that exposure to PAHs has a causational effect on breast cancer in humans, yet this interaction is not clearly understood. In vitro and animal-based studies have consistently revealed that exposure to PAHs deleteriously affects breast tissue, but there is no definitive link between these compounds and breast cancer.

(C) 2015 S. Karger GmbH, Freiburg

\section{Introduction}

Polycyclic aromatic hydrocarbons (PAHs) exist and persist in the atmosphere due to the incomplete combustion of fossil fuels, and are established human carcinogens in the lungs. Additionally, oral uptake of PAHs may also occur via consumption of smoked and grilled meat and fish, and dermal exposure to PAHs may result from the use of consumer products that contain black rubber. However, the influence of PAHs on the development of breast cancer, the most commonly diagnosed cancer in women worldwide, remains unclear [1]. Given that established risk factors only account for approximately $41 \%$ of the breast cancer cases in the USA, researchers have sought to uncover environmental factors involved in breast cancer development $[2,3]$.

PAHs are a group of over 100 chemicals, usually occurring as mixtures. According to the Agency for Toxic Substances and Disease Registry, PAHs have been identified in 600 of the 1,430 National Priorities List sites identified by the United States Environmental Protection Agency (USEPA) [4]. PAHs are produced due to the incomplete combustion of hydrocarbons, fossil fuels (coal and gas), and biomass for energy production. PAHs produced from these processes include: benz(a)pyrene $(\mathrm{BaP})$, dibenz(ah)anthracene (DB(ah)A), 1-nitropyrene (1-NP), and 7,12-dimethylbenz(a) anthracene (DMBA), as well as the monocyclic hydrocarbon benzene, all of which are established experimental breast carcinogens [3]. Currently, benzene, $\mathrm{BaP}$, and $\mathrm{DB}(\mathrm{ah}) \mathrm{A}$ are listed as priority pollutants by the USEPA; priority pollutants are chemical pollutants the USEPA regulates and for which it has established analytical test methods [5]. The concentration of benzene in the atmosphere is mainly attributed to automobile use; as such, the highest concentrations exist around highways and high-traffic urban areas. The benzene content in gasoline ranges from $<1 \%$ to $15 \%$, depending on the country [6]. Benzene also serves as a chemical intermediate for various products, including ethylbenzene (used to make styrene), many of which ultimately aid in the production of plastics and pesticides [6]. Benzene and other PAHs are also produced from the 
burning of wood and organic material, and it is found in tobacco smoke. Moreover, humans can also be exposed to PAHs through the consumption of smoked and grilled foods. As a hydrophobic compound, PAHs can be absorbed through the dermis [7]. It has been established that benzene, through inhalation or ingestion, is a multipotential carcinogen. The PAHs BaP, DB(ah)A, and 1-NP have all been proven to induce breast tumors in animals [3]

\section{Results and Discussion}

The breasts are particularly susceptible to aromatic carcinogenesis. Fat cells can store and concentrate aromatic carcinogens [2], and breasts are largely composed of fat. PAHs can be harbored in mammary and other fat tissues [3]. Several in vitro studies have shown that, in breast epithelial tissue, PAHs are metabolized to their most potent and deleterious state [8-10], ultimately affecting cellular morphology as well as cellular division, growth, and repair. Furthermore, the cells in these studies displayed anchorage independence, a potential reflection of tumorigenicity [10]. Multiple experiments have shown that PAH induces mammary neoplasms in animals $[11,12]$. p53 mutations have been implicated in breast cancer and, in fact, approximately half of all human cancers have a p53 mutation [13-15]. Mordukhovich et al. [16] concluded that PAHs may alter the effect, type, and number of p53 mutations.

The use of biomarkers in measuring PAH-DNA adducts has been implemented to assess exposure to eliminate the bias that is inherent with self-reporting measures in case-control studies that have investigated the link between PAHs and cancer. Adducts appear to be instrumental in the development of mutation and cancer, although the precise relationship is not understood [17]. Adduct levels reflect exposure dose as well as how the body responds to this exposure, which is partially attributable to genetic variability $[18,19]$. In essence, exposure and repair or detoxification are at odds with one another; thus, when either exposure exceeds detoxification or detoxification alone is insufficient, PAH-DNA adducts form [7], predisposing one to abnormal cellular growth and division. A study conducted by Rundle et al. [17] that controlled for known breast cancer risk factors indicated that inter-individual variation in metabolic and/or DNA repair pathways may play a significant role in breast cancer. Rundle and colleagues also investigated the relationship between PAHs and polymorphisms in the glutathione S-transferase M1 (GSTM1) gene, which is known to be highly polymorphic and involved in the detoxification of carcinogenic compounds [20]. Rundle et al. [8] concluded that GSTM1 polymorphisms play a role in predicting adduct levels for cases but not controls. Evidence suggests that the XPD gene (also called ERCC2), which has numerous single-nucleotide polymorphisms and is involved in nucleotide excision repair, may influence an individual's ability to repair DNA from bulky DNA adducts [21]. Polymorphisms in the XPD gene, such as the Asn/Asn or Gln/Gln genotypes, may be associated with greater PAH-DNA adduct levels in tumor tissue [22]. Shen et al. [23] investigated the relationship of polymorphisms in X-ray repair cross-complimenting group 1
(XRCC1), an important DNA base excision repair gene, and breast cancer risk. Two polymorphisms, Arg194Trp and Arg399Gln, do not appear to directly influence breast cancer risk. Among neversmokers, a suggestive additive interaction was observed between the XRCC1 399Gln allele and PAH-DNA adducts. Yet, XRCC1 194 Trp carriers, through high fruit and vegetable consumption, may have a decreased breast cancer risk.

In 1996, Li et al. [2] assessed aromatic adducts in human tissue from breast cancer patients undergoing mastectomy versus breast tissue from non-cancer patients undergoing reduction mammoplasty. Aromatic DNA adducts, although detected in all samples, were significantly higher in the breast cancer patients versus the healthy controls $(\mathrm{p}<0.01)$; therefore, these results indicate that PAHs may play a role in the development of breast cancer. The Long Island Breast Cancer Study Project (LIBCSP), conducted from 1992 to 1996 in response to concerns about environmental effects on breast cancer risk in Long Island, NY, showed that the average level of PAH-DNA adducts measured per $10^{8}$ nucleotides was only minimally greater in breast cancer patients than in the controls (5.48 vs. 5.37). Additionally, the data suggested that the effect of PAH adduct levels may be enhanced in premenopausal women (overall response (OR) 1.56) [24]. Rundle et al. [8] conducted a case-control study including women with benign breast disease (BBD) as controls. This study showed that PAH-DNA adduct levels were significantly greater in tumor tissue from breast cancer patients versus benign tissue from women with BBD (OR 2.40). However, there was no significance between adduct levels in non-tumor tissue from breast cancer patients versus the $\mathrm{BBD}$ controls (OR 1.97).

The LIBCSP analyzed peripheral mononuclear cells and not breast tissue to assess the PAH-DNA adducts; Gammon et al. [24] and Perera and Rundle [25] indicate that this method may not be as accurate, yielding lower measurements than from breast tissue. Rundle et al. [8] have also opted to include women diagnosed with $\mathrm{BBD}$ as controls, in contrast to tissue from women undergoing reduction mammoplasty. However, they acknowledge that selection bias may inadvertently result from selecting women with BBD as controls. Rundle et al. [8] note that tissue adducts assessed by immunohistochemical assays, as in their study, are scored by individuals and there is no standard method for scoring; thus, there may be variability between reviewers and studies. Regardless of the tissue from which PAHs are assessed, it is not a strong measure of long-term exposure [24]. A possible confounder associated with the LIBCSP was attenuation. The results of studies with larger sample sizes can become nullified, versus smaller studies in which variations are more evident [24, 26, 27].

In examining the potential relationship between PAHs and breast cancer, it is also crucial to consider the geographic location and socioeconomic status of the patients. Studies conducted in Western New York in 2005 and 2007 have noted the necessity of investigating exposure to PAHs in relation to the location where patients resided during various critical periods in their lives, such as at the times of menarche and first birth $[28,29]$. Furthermore, in response to reports of high breast cancer mortality rates in the North- 
eastern USA, a 1997 study of the region was conducted; this study found statistically significant clusters of breast cancer deaths in the New York City-Philadelphia metropolitan area, particularly in affluent suburban communities with ample access to health care [30]. The researchers noted that they were unaware of any studies indicating greater exposure to PAHs in these communities, but it is nonetheless worth considering environmental conditions as a contributing factor to breast cancer mortality rates, as such factors can vary widely with location. Subsequent research conducted among breast cancer patients in one such significant suburban cluster Long Island, NY - reported that PAH-DNA adduct levels were higher, albeit not significantly, among this area's breast cancer patients than in the control population [31]. The researchers in this study also observed a 50\% increase in breast cancer risk for patients in the highest quintile of PAH-DNA adduct levels, even after accounting for potential confounding factors. Such results indicate that further research is required to understand the risks of exposure to PAHs as they relate to geographic and socioeconomic factors.

\section{Conclusions}

PAHs, released by use of fossil fuels and biomass for energy production, are established carcinogens to other parts of the body $[3,19]$. Evidence suggests that exposure to PAHs has a causational effect on breast cancer in humans, yet this interaction is not clearly understood. In vitro and animal-based studies have consistently revealed that exposure to PAHs deleteriously affects breast tissue, while the implementation of biomarkers has provided promising insights regarding PAH-DNA adducts in breast cancer. Environmental exposure to PAHs produced by fuel combustion, especially as mediated by geographic region and socioeconomic status, must be taken into account as researchers strive to understand the effects of PAHs on breast cancer risk.

\section{Disclosure Statement}

None of the authors have anything to disclose or have any conflicts of interest.

\section{References}

1 Global Cancer Facts \& Figures, ed 2. www.cancer.org/ acs/groups/content/@epidemiologysurveilance/documents/ document/acspc-027766.pdf.

2 Li D, Wang M, Dhingra K, Hittelman WN: Aromatic DNA adducts in adjacent tissues of breast cancer patients: clues to breast cancer etiology. Cancer Res 1996; 56:287-293.

3 Morris JJ, Seifter E: The role of aromatic hydrocarbons in the genesis of breast cancer. Med Hypotheses 1992; 38:177-184

4 ToxFAQs $^{\mathrm{TM}}$ for Polycyclic Aromatic Hydrocarbons (PAHs). www.atsdr.cdc.gov/toxfaqs/tf.asp?id=121e tid $=25$

5 Priority pollutants. http://water.epa.gov/scitech/methods/ cwa/pollutants.cfm.

6 Maltoni C, Ciliberti A, Cotti G, Conti B, Belpoggi F: Benzene, an experimental multipotential carcinogen: results of the long-term bioassays performed at the Bologna Institute of Oncology. Environ Health Perspect 1989;82:109-124

7 Sagiv SK, Gaudet MM, Eng SM, Abrahamson PE, Shantakumar S, Teitelbaum SL, Bell P, Thomas JA, Neugut AI, Santella RM, et al.: Polycyclic aromatic hydrocarbon-DNA adducts and survival among women with breast cancer. Environ Res 2009;109:287-291.

$>8$ Rundle A, Tang D, Hibshoosh H, Schnabel F, Kelly A, Levine R, Zhou J, Link B, Perera F: Molecular epidemiologic studies of polycyclic aromatic hydrocarbonDNA adducts and breast cancer. Environ Mol Mutagen 2002;39:201-207.

-9 Eldridge SR, Gould MN, Butterworth BE: Genotoxicity of environmental agents in human mammary epithelial cells. Cancer Res 1992;52:5617-5621.

10 Calaf G, Russo J: Transformation of human breast epithelial cells by chemical carcinogens. Carcinogenesis 1993;14:483-492.

11 Hecht SS: Tobacco smoke carcinogens and breast cancer. Environ Mol Mutagen 2002;39:119-126.

12 el-Bayoumy K, Chae YH, Upadhyaya P, Rivenson A, Kurtzke C, Reddy B, Hecht SS: Comparative tumorigenicity of benzo[a]pyrene, 1-nitropyrene and 2-amino-1-methyl-6-phenylimidazo[4,5-b]pyridine administered by gavage to female CD rats. Carcinogenesis 1995;16:431-434.
Greenblatt MS, Bennett WP, Hollstein M, Harris CC: Mutations in the p53 tumor suppressor gene: clues to cancer etiology and molecular pathogenesis. Cancer Res 1994;54:4855-4878.

14 Goldman R, Shields PG: Molecular epidemiology of breast cancer. In Vivo 1998;12:43-48.

15 Biggs PJ, Warren W, Venitt S, Stratton MR: Does a genotoxic carcinogen contribute to human breast cancer? The value of mutational spectra in unravelling the aetiology of cancer. Mutagenesis 1993;8:275-283.

16 Mordukhovich I, Rossner P Jr, Terry MB, Santella R, Zhang YJ, Hibshoosh H, Memeo L, Mansukhani M, Long CM, Garbowski G, et al.: Associations between polycyclic aromatic hydrocarbon-related exposures and p53 mutations in breast tumors. Environ Health Perspect 2010;118:511-518.

17 Rundle A, Tang D, Hibshoosh H, Estabrook A, Schnabel F, Cao W, Grumet S, Perera FP: The relationship between genetic damage from polycyclic aromatic hydrocarbons in breast tissue and breast cancer. Carcinogenesis 2000;21:1281-1289.

18 Santella RM: Immunological methods for detection of carcinogen-DNA damage in humans. Cancer Epidemiol Biomarkers Prev 1999;8:733-739.

19 Gammon MD, Santella RM: PAH, genetic susceptibil ity and breast cancer risk: an update from the Long Island Breast Cancer Study Project. Eur J Cancer 2008; 44:636-640.

20 GSTM1 glutathione S-transferase mu 1 [Homo sapiens (human)].www.ncbi.nlm.nih.gov/gene/2944.

21 Terry MB, Gammon MD, Zhang FF, Eng SM, Sagiv SK, Paykin AB, Wang Q, Hayes S, Teitelbaum SL, Neugut AI, et al.: Polymorphism in the DNA repair gene XPD, polycyclic aromatic hydrocarbon-DNA adducts, cigarette smoking, and breast cancer risk. Cancer Epidemiol Biomarkers Prev 2004;13:2053-2058.

22 Tang D, Cho S, Rundle A, Chen S, Phillips D, Zhou J, Hsu Y, Schnabel F, Estabrook A, Perera FP: Polymorphisms in the DNA repair enzyme XPD are associated with increased levels of PAH-DNA adducts in a casecontrol study of breast cancer. Breast Cancer Res Treat 2002;75:159-166.
3 Shen J, Gammon MD, Terry MB, Wang L, Wang Q, Zhang F, Teitelbaum SL, Eng SM, Sagiv SK, Gaudet $\mathrm{MM}$, et al.: Polymorphisms in XRCC1 modify the association between polycyclic aromatic hydrocarbonDNA adducts, cigarette smoking, dietary antioxidants, and breast cancer risk. Cancer Epidemiol Biomarkers Prev 2005; 14:336-342.

24 Gammon MD, Sagiv SK, Eng SM, Shantakumar S, Gaudet MM, Teitelbaum SL, Britton JA, Terry MB, Wang LW, Wang Q, et al.: Polycyclic aromatic hydrocarbon-DNA adducts and breast cancer: a pooled analysis. Arch Environ Health 2004;59:640-649.

25 Perera F, Rundle A: Correspondence re: Gammon et al, Environmental toxins and breast cancer on Long Island. I. Polycyclic aromatic hydrocarbon DNA adducts. 11, 677-685, 2002. Cancer Epidemiol Biomarkers Prev 2003;12:75; author reply 75-76.

26 Hirschhorn JN, Lohmueller K, Byrne E, Hirschhorn K: A comprehensive review of genetic association studies. Genet Med 2002;4:45-61.

27 Ioannidis JPA, Ntzani EE, Trikalinos TA, Contopoulos-Ioannidis DG: Replication validity of genetic association studies. Nat Genet 2001;29:306-309.

28 Bonner MR, Han D, Nie J, Rogerson P, Vena JE, Muti P, Trevisan M, Edge SB, Freudenheim JL: Breast cancer risk and exposure in early life to polycyclic aromatic hydrocarbons using total suspended particulates as a proxy measure. Cancer Epidemiol Biomarkers Prev 2005; 14:53-60.

29 Nie J, Beyea J, Bonner MR, Han D, Vena JE, Rogerson P, Vito D, Muti P, Trevisan M, Edge SB, et al.: Exposure to traffic emissions throughout life and risk of breast cancer: the Western New York Exposures and Breast Cancer (WEB) study. Cancer Causes Control 2007;18:947-955.

30 Kulldorff M, Feuer EJ, Miller BA, Freedman LS: Breast cancer clusters in the northeast United States: a geographic analysis. Am J Epidemiol 1997;146:161-170.

31 Gammon MD, Santella RM, Neugut AI, Eng SM, Teitelbaum SL, Paykin A, Levin B, Terry MB, Young TL, Wang LW, et al.: Environmental toxins and breast cancer on Long Island. I. Polycyclic aromatic hydrocarbon DNA adducts. Cancer Epidemiol Biomarkers Prev 2002;11:677-685. 